\title{
ISLANDS - SOIL PATCHES AND PLANT COMMUNITY DYNAMICS ON A NEW OIL SANDS RECLAMATION DESIGN1
}

\author{
Bradley D. Pinno ${ }^{2}$, Ira Sherr, Ruth C. Errington, and Krista Shea
}

\begin{abstract}
The goal of land reclamation after oil sands mining in the boreal forest of northern Alberta, Canada is to re-establish functioning forest ecosystems, including the development of a natural plant community. Reclamation practices include the use of operational reclamation soils derived from upland forest soils (referred to as forest floor-mineral mix (FFMM)), which has higher plant diversity, and lowland based peat-mineral mix (PMM), which has greater tree regeneration. Building from experience in forest harvesting practices and natural landscape patterns, the "Islands" reclamation concept was put into practice in a new reclamation area established in 2015 with patches or islands of differing sizes and shapes of FFMM placed within a matrix of the more abundant PMM. These islands of FFMM are intended to serve as lifeboats and colonization centres for native biota. Initial studies are focusing on determining the optimal size and spacing of the FFMM patches. Plant species area curves were developed and show that patch sizes of at least $671-960 \mathrm{~m}^{2}$ are recommended to allow initial establishment of native plant species, and in particular woody species, with smaller patch sizes favouring non-native weedy species. Initial spatial patterns indicate no relationship between plant species richness and distance to FFMM - PMM soil boundary with the rate and distance of spread of native plants from the FFMM patches being an important monitoring consideration in future years. This work on the Islands approach will help in the development of more efficient and effective reclamation practices which take advantage of the ecological differences in available reclamation soils.
\end{abstract}

Keywords - forest floor-mineral mix, peat-mineral mix, plant community, reclamation soils, mineable oil sands, Alberta

${ }^{1}$ Oral paper to be presented at the 2016 National Meeting of the American Society of Mining and Reclamation, Spokane, WA, Reclaiming the West, June 4-9, 2016. R.I. Barnhisel (Ed) Published by ASMR; 1305 Weathervane Dr., Champaign, IL 61821.

${ }^{2}$ Bradley D. Pinno and Ruth C. Errington are with Natural Resources Canada, Canadian Forest Service, Northern Forestry Centre, Edmonton, Alberta, Canada; Ira Sherr and Krista Shea are with Canadian Natural Resources Limited, Horizon Oil Sands, Fort McMurray, Alberta, Canada.

Journal American Society of Mining and Reclamation, 2016 Volume 5, Issue 1 pp 28 - 44 DOI: http://doi.org/10.21000/JASMR16010028 
JASMR, 2016 Volume 5 Issue 1

\section{Introduction}

Oil sands mining has currently disturbed an area of $896 \mathrm{~km}^{2}$ in the boreal forest of northeastern Alberta, Canada, and with a total mineable oil sands area of $4,800 \mathrm{~km}^{2}$ this disturbance will continue to grow in the coming decades. This disturbance includes areas for mining, infrastructure, bitumen processing, and other associated developments. After these operations are completed, the land must be reclaimed to an equivalent land capability with the overall goal of creating a functional and self-sustaining boreal forest ecosystem similar to natural boreal forests in the region (Government of Alberta, 2015). This implies more than just growing trees, but includes many ecosystem components including soils, understory plants, trees, and wildlife along with ecosystem

processes such as primary productivity and nutrient cycling. Understory plants are a particularly important component as they form the majority of plant diversity in boreal forests, are critical in nutrient cycling processes (Hart and Chen, 2006), and provide food and habitat for various wildlife (Venier and Pearce, 2007).

Current reclamation operations to create forest land first involve constructing landforms from overburden or tailings materials. These landforms are then capped with reconstructed soils rich in organic matter from either upland or lowland origin (Audet et al., 2015). To date, most reclamation in the mineable oil sands area has been completed with only two main soil types which have very different properties, peat-mineral mix (PMM) and forest floor-mineral mix (FFMM). PMM is derived from lowland peat deposits mixed with underlying mineral soil and has high organic matter content, high water holding capacity, and greater potential for natural tree seedling establishment (Pinno and Errington, 2015). PMM is also more widely available, as over half of the existing landscape is lowland peat bogs and fens. Therefore, it has been used for the majority of reclamation to date and will be the most commonly used reclamation soil in the future at most mine sites. FFMM, on the other hand, is derived from upland forest soils with the organic forest floor layer being mixed with underlying mineral soil. FFMM has lower organic matter content and water holding capacity (Pinno and Errington, 2015), but does support higher levels of initial biodiversity and biomass in the plant community (Errington and Pinno, 2016; Archibald, 2014; Mackenzie and Naeth, 2010) than PMM. This biological legacy of the past forest is mainly from the plant propagules, seeds, roots, and rhizomes found in the organic forest floor layer and upper mineral soil. However, this higher diversity leads to increased plant competition and decreased natural tree establishment (Pinno and Errington, 2015). FFMM is the recommended surface soil 
application (Alberta Environment and Water, 2012), but it is limited in its availability such that only approximately $35 \%$ of the land will be reclaimed with this soil type under current practices. Note that FFMM is also referred to operationally as "topsoil," "upland surface soil," or "LFH" (Macyk and Drozdowski, 2008), but we have chosen to use the term FFMM here as it best reflects the nature of the soil and is consistent with our past research.

Reclamation soils have normally been applied as relatively large, homogeneous areas for each different soil type. For example, Fig. 1a shows a typical oil sands reclamation design of a reclaimed overburden dump constructed in 2011 with four main soil applications of approximately 20 ha each in size. However, these large blocks of single soil types may not be providing the optimal use of the limited reclamation soil resources. Moving forward, one operational reclamation challenge is how to maximize the benefits of each reclamation soil type across the landscape within the constraints of limited amounts of each material, especially FFMM, and the differing ecological benefits of each. One of the first attempts at combining these soils operationally is the reclamation concept known as "Islands" where the two soil types are integrated with a matrix of PMM and islands of FFMM within it (Fig. 1b).

The Islands approach builds off past reclamation research (e.g., Burley et al., 2005) as well as from boreal forest management practices which leave residual patches (islands) of forest in harvested areas (e.g., Baker et al. 2015; Gustafsson et al., 2015) and natural disturbances, such as fire, which also leave unburnt portions of forest (e.g., Huggard et al. 2015; Delong and Tanner, 1996). These residual patches have substantial benefits to biodiversity by serving as lifeboats or colonization centres for species to be retained in the post-disturbance forest and by facilitating reestablishment of species into the surrounding area (Vanha-Majamaa and Jalonen, 2001). The effectiveness of these patches depends on their size and spatial arrangement with larger patches supporting more species and the distance between patches determining the length of time it takes a specific species to colonize the surrounding area (Bradbury, 2004). Of particular importance in reclaimed areas are non-native species, some of which have the ability to alter native plant patterns and communities (Powell et al., 2013).

The specific ecological and operational questions we are trying to address in this first Islands reclamation attempt are: 1) How big should the FFMM patches be to optimize plant diversity? and, 2) How far apart should the FFMM patches be? To examine the first question we developed reclamation species area curves for vascular plants (including natives, non-natives, and woody 
species) from $1 \mathrm{~m}^{2}$ up to $2,860 \mathrm{~m}^{2}$ in total area while for the second question we looked at plant diversity along transects between soil types in both older ( $5^{\text {th }}$ growing season) and newer (Islands, $1^{\text {st }}$ growing season) reclamation areas to determine how quickly plants from FFMM are colonizing adjacent PMM.

a)

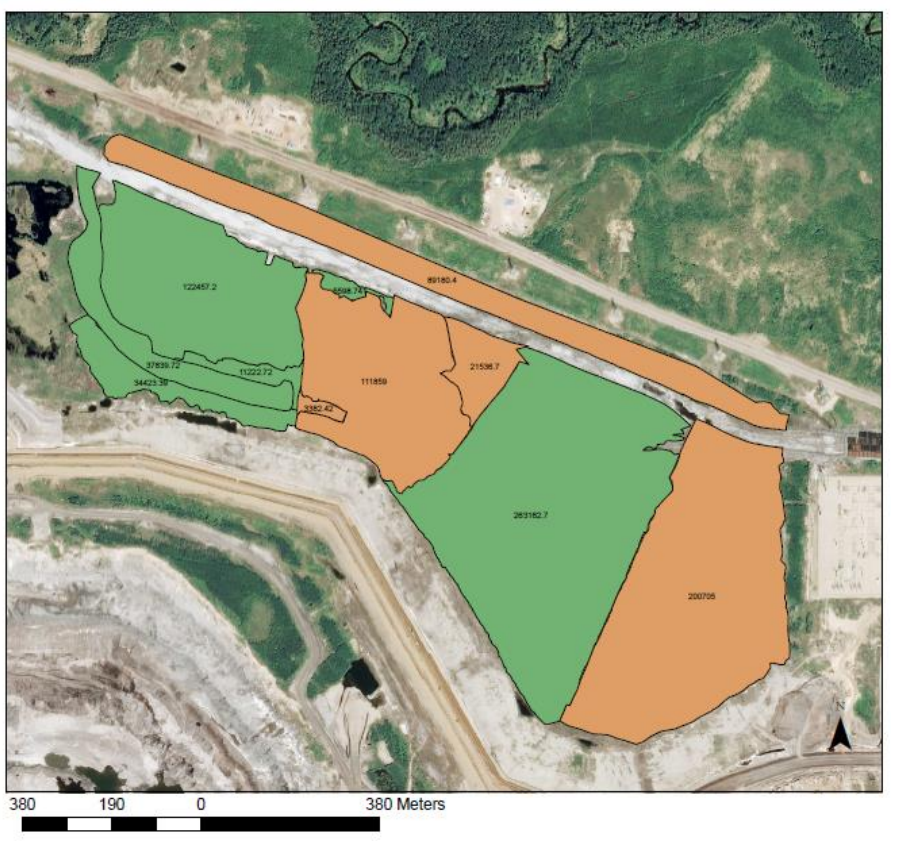

b)

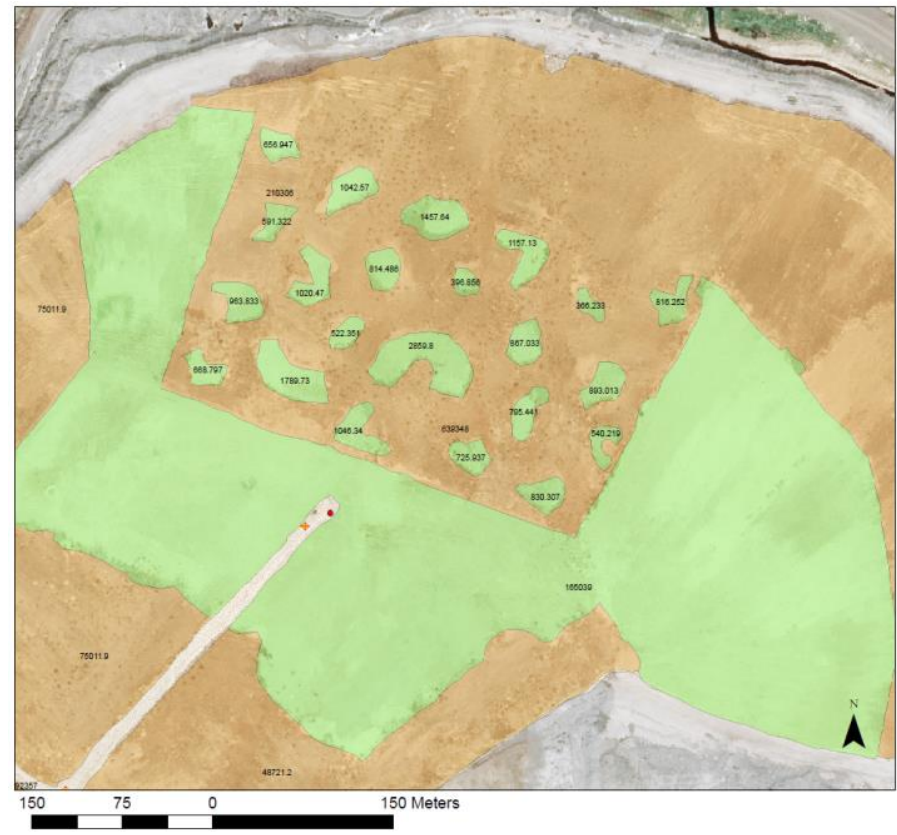

Figure 1 a) Five-year old reclamation site with the traditional approach of applying soil in large patches of approximately 20 ha each with total size of 88.6 ha. b) One-year-old Islands area with smaller patches of FFMM within a matrix of PMM with a total size of the Islands area of 9.5 ha. 
JASMR, 2016 Volume 5 Issue 1

\section{Methods}

This study was located on an oil sands mine northwest of Fort McMurray, Alberta, Canada within the boreal mixedwood ecoregion (Beckingham and Archibald, 1996). The climate for this region is continental with an average annual temperature of $1{ }^{\circ} \mathrm{C}$ and annual precipitation of 419 mm (Fort McMurray, 1981-2010 climate normals from Environment Canada). The landscape consists of upland forests of mixtures of mainly trembling aspen (Populus tremuloides), white spruce (Picea glauca), and jack pine (Pinus banksiana) with extensive areas of lowlands, mainly peat forming bogs and fens, which support black spruce (Picea mariana) and tamarack (Larix laricina).

Open-pit mining for bitumen ore involves removal of overburden materials and salvaging of surface soils (both mineral and organic) to be used in future reclamation. The two reclamation areas studied here are comprised of overburden topped with sections of both directly-placed PMM and FFMM. The one-year-old site established in 2015 is the first attempt at implementing the Islands approach. It is $9.5 \mathrm{ha}$ in size, and is part of a larger reclamation area on a tailings dyke structure constructed of overburden material topped with $20 \mathrm{~cm}$ of either PMM or FFMM. The spatial structure of Islands is a matrix of PMM with pre-planned and delineated islands of FFMM ranging in size from $366-2,860 \mathrm{~m}^{2}$ (Fig. 1b). For comparison, an older site with the same reclamation soils was used to evaluate the potential for species movement across soil boundaries. The five-year-old site is an 88.6 ha operational reclamation area constructed in 2011 on an overburden dump which features four large non-replicated blocks of directly placed PMM and FFMM (approximately $50 \mathrm{~cm}$ depth) crossed with a fertilizer application $\left(200 \mathrm{~kg} \mathrm{~N} \mathrm{ha}^{-1}\right.$ total NPKS 29.9-9.1-9.1-9.1 fertilizer applied over the first two growing seasons) on a single block of each soil type (Fig. 1a). For the purposes of this study only the unfertilized blocks were compared since the one-year-old Islands site was not fertilized.

Sampling plots were established in 2015 in each reclamation area (total of 35 at one-year-old Islands site and 12 at the five-year-old site) in both soil types to measure basic soil and site characteristics. Natural tree seedling establishment density was measured in $3.99 \mathrm{~m}$ radius plots. Both sites were planted with conifers at a density of between 1,200 and 1,600 stems ha ${ }^{-1}$ so we focused our comparisons on the natural establishment of deciduous seedlings of which over $80 \%$ were trembling aspen with the remainder being balsam poplar (Populus balsamifera) and white 
birch (Betula papyrifera). Total leaf area index above ground level including all trees and understory vegetation was measured at peak vegetation development (LAI-2200C, LI-COR Biosciences, Lincoln, NE). Soil volumetric water content was measured at $12 \mathrm{~cm}$ depth three times throughout the growing season (FieldScout TDR 300, Spectrum Technologies Inc., Aurora, IL). Four volumetric soil samples from $0-15 \mathrm{~cm}$ depth were collected and then analyzed in the lab for $\mathrm{pH}$. ANOVA was used to compare general soil and site characteristics between soil type at each site separately (Systat 13.1, Systat Software Inc., Chicago, IL, USA).

Species area curves are the relationship between a specified area and the number of species found within that area with larger areas tending to contain more species. For the FFMM patches, species area curves were based on vascular plant species richness (number of species present) in areas from $1-2,860 \mathrm{~m}^{2}$. Within the Islands area, four $1 \mathrm{~m}^{2}$ quadrats were established at each sampling location, one quadrat at $10 \mathrm{~m}$ from the centre of the plot in each cardinal direction except in four cases where irregular shape or small patch sizes resulted in a modified quadrat arrangement. Walkaround surveys were then conducted to identify all plant species within the area enclosed by the quadrats (314 $\mathrm{m}^{2}$ unless modified). Ten individual FFMM patches ranging in size from $366-$ $2,860 \mathrm{~m}^{2}$ were also surveyed completely to identify all species present. We recorded the total number of species as well as the number of native, non-native, and woody species present at each sampling survey. Species area curves were fitted using a power function with values from 1, 4, and $314 \mathrm{~m}^{2}$ sampling areas averaged. To determine the minimum desirable patch size for FFMM islands, we set the threshold at $75 \%$ of species found in the largest patch (58). For comparison, this is exactly the same number of species (58) found after wildfire in a nearby natural aspendominated mixedwood forest ( $\mathrm{Li}$ et al., 2014) identified from a total sampling area of approximately $1,800 \mathrm{~m}^{2}$.

To determine early species movement across soil type boundaries through vegetative spread or short distance seeding, we established a series of ten transects along the boundaries between PMM and FFMM at both reclamation sites. Each transect was a total of $30 \mathrm{~m}$ in length with $20 \mathrm{~m}$ in PMM and $10 \mathrm{~m}$ in FFMM due to the small size of some FFMM islands. Quadrats of $1 \mathrm{~m}^{2}$ were established at each metre from $0-10$ and then at 15 and $20 \mathrm{~m}$ into the PMM from the soil interface in the one-year-old Islands site and at $0,1,3,5,10,15$, and $20 \mathrm{~m}$ from the soil interface in the five-year-old site. In each quadrat, a list of all plant species was determined along with the number of native, non-native, and woody species. Regression tree analysis was used to evaluate species 
richness per quadrat based on distance from the soil interface at both reclamation sites separately. The question is, if quadrats closer to the soil interface have higher plant richness than quadrats further, was this is an indication that species are moving from one soil type to the other? To further examine the patterns of plant diversity in the different soil types, we used data from the quadrats across the soil type interface at the one-year-old site to compare the relative occurrence (i.e., frequency of common vs rare species) of native and non-native species in both FFMM and PMM.

\section{Results}

The FFMM and PMM reclamation soils had distinct characteristics in both the one- and fiveyear-old sites with soil moisture, soil $\mathrm{pH}$, leaf area development, and understory species richness being higher in FFMM than PMM and deciduous tree seedling density being greater in PMM than FFMM at both reclamation sites (Table 1).

Table 1. Soil and site characteristics for each soil type. Values are average (standard deviation).

\begin{tabular}{|c|c|c|c|c|c|c|}
\hline & \multicolumn{3}{|c|}{1 Year Old Site } & \multicolumn{3}{|c|}{5 Year Old Site } \\
\hline & FFMM & PMM & $p$ & FFMM & PMM & $p$ \\
\hline Volumetric water content (\%) & $22.9(4.49)$ & $35.1(4.45)$ & $<0.001$ & $10.5(1.89)$ & $18.2(4.64)$ & 0.004 \\
\hline Soil temperature $\left({ }^{\circ} \mathrm{C}\right)$ & $17.3(1.72)$ & $14.3(1.90)$ & $<0.001$ & $16.2(1.87)$ & $17.3(4.64)$ & 0.242 \\
\hline Soil pH & $6.9(0.52)$ & $6.2(1.00)$ & $<0.001$ & $7.2(0.56)$ & $6.4(1.28)$ & $<0.001$ \\
\hline Leaf area index $\left(\mathrm{m}^{2} \mathrm{~m}^{-2}\right)$ & $1.22(1.15)$ & $0.22(0.19)$ & 0.009 & $2.62(0.76)$ & $0.48(0.24)$ & $<0.001$ \\
\hline Tree seedling density (stems ha ${ }^{-1}$ ) & $631(863)$ & $19,114(17,314)$ & $<0.001$ & $7,448(9,284)$ & $12,678(16,423)$ & 0.273 \\
\hline
\end{tabular}

Based on the species area curve developed for native species in FFMM patches at the one-year old Islands site, a minimum patch size of $671 \mathrm{~m}^{2}$ would be required to capture $75 \%$ of the species diversity found in the largest patch (Fig. 2a). The curves for non-native and woody species (Fig. 2b) show differing ecological responses between species groups with non-native species richness reaching a relatively flat asymptote at a smaller patch size than woody species richness which continues to increase more with patch size. For comparison, non-native species richness reaches $75 \%$ of maximum non-native richness in the largest patch size at only $170 \mathrm{~m}^{2}$ compared to woody species which reach this same criteria at $960 \mathrm{~m}^{2}$. 

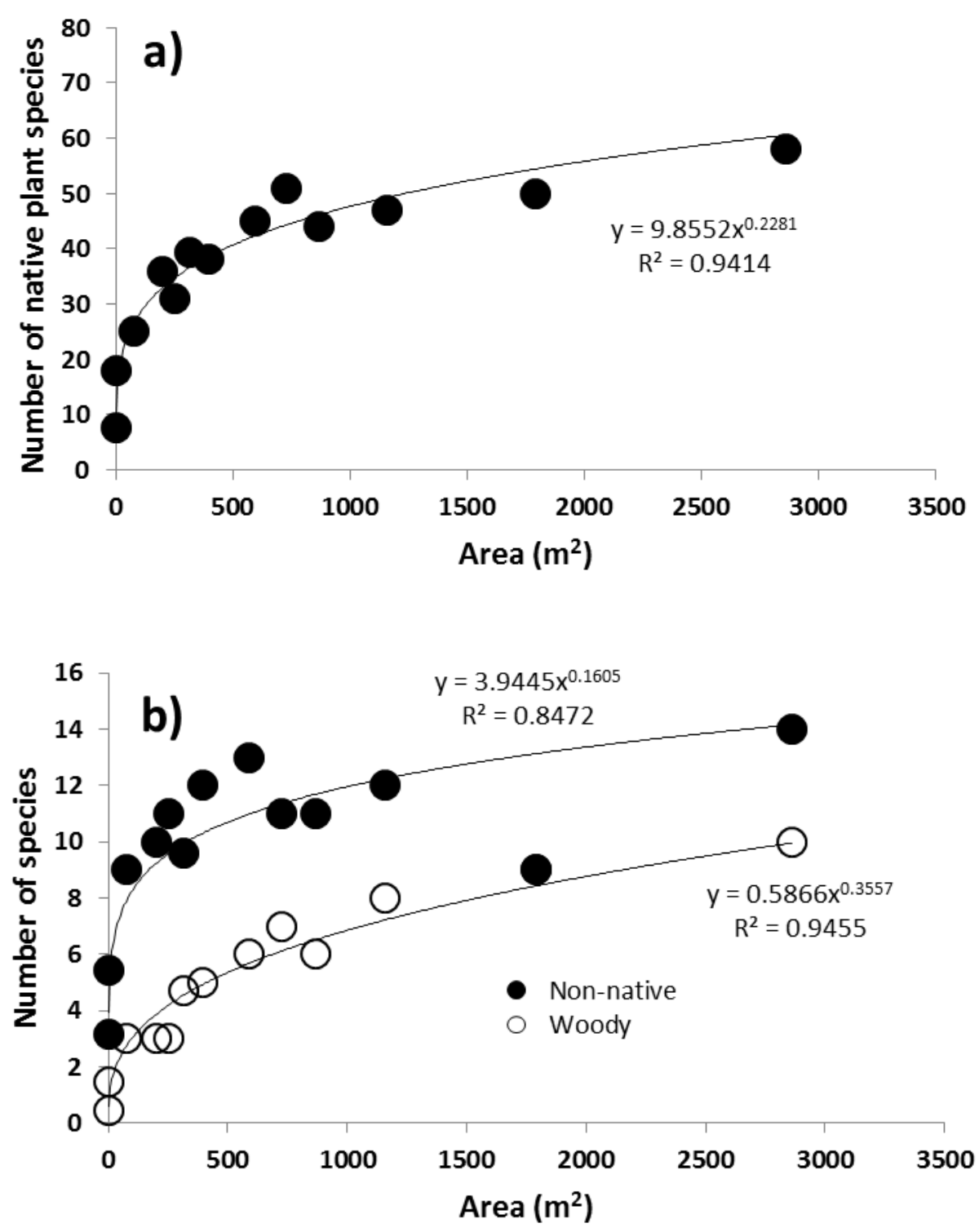

Figure 2. Species area curves for all FFMM for: a) native species and b) non-native and woody species.

Plant species richness measured on transects across soil type boundaries show differing patterns based on species groups and reclamation age. Native species richness is greatest in FFMM at both sites with no significant difference $(p>0.05)$ in richness within each soil type based on distance to soil interface. In the five-year-old site the overall species richness is greater but the spatial pattern is similar (Fig. 3a). The total native species pool (i.e., number of species present) is greater in FFMM than PMM and increases over time with a greater increase in FFMM (27 more species) than in PMM (6 more species) (Table 2). The overall native species richness was also 
driven by many rare species, with only a single occurrence in both FFMM and PMM. The four most common species, Agropyron trachycaulum, Lathyrus ochroleucus, Potentilla norvegica, and Agrostis scabra, comprised only $32 \%$ of the total native plant occurrences (Fig. 4).

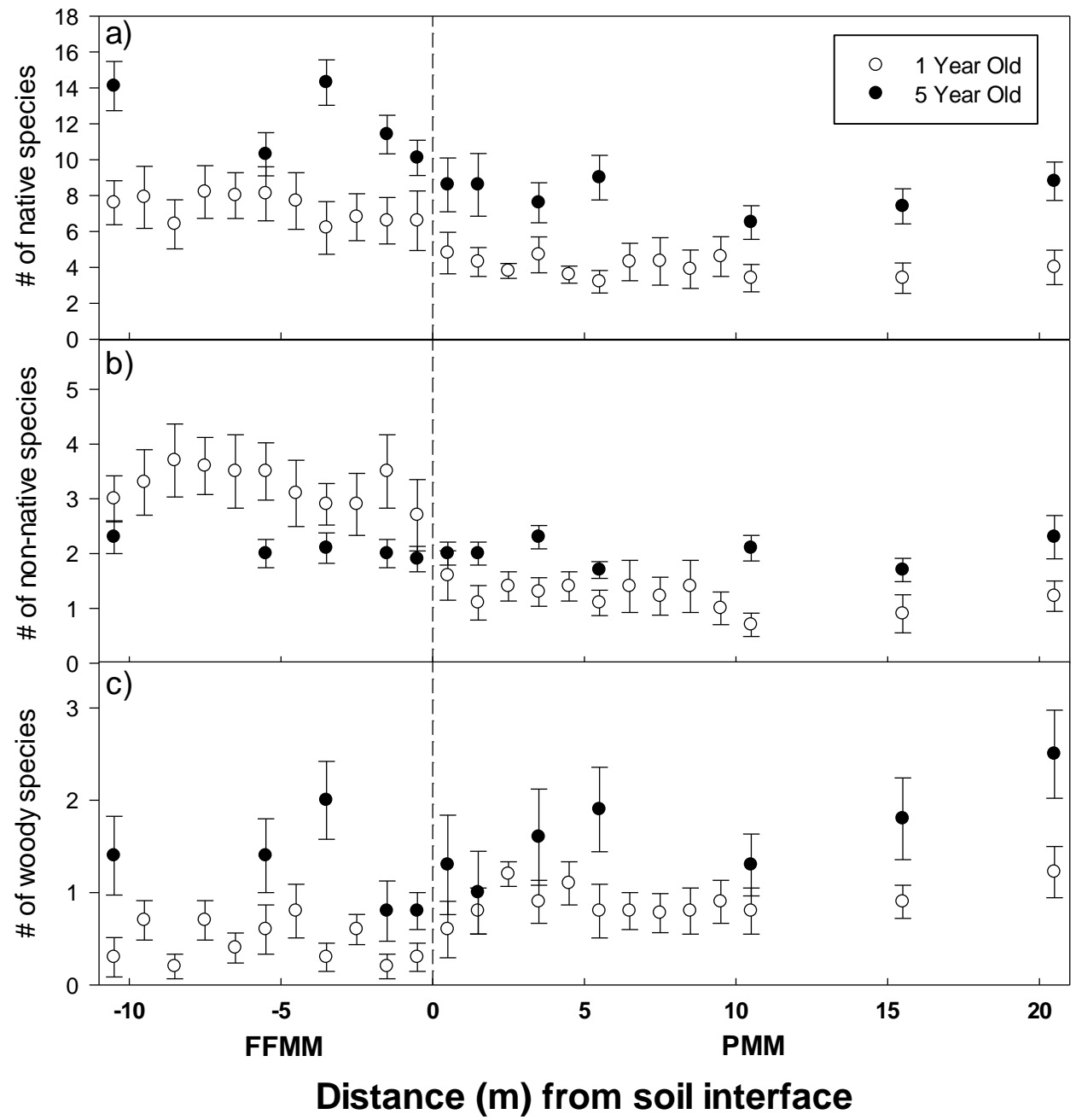

Figure 3. Species diversity along transects between FFMM and PMM for: a) native species, b) non-native species, and c) woody species. 
Table 2. Total species pool (i.e., number of species) recorded in all quadrats combined along transects between soil types.

\begin{tabular}{llcc}
\hline & & 1 Year OldSite & 5 Year Old Site \\
\hline \multirow{2}{*}{ FFMM } & Native & 71 & 98 \\
& Non-native & 16 & 10 \\
& Woody & 9 & 17 \\
\multirow{3}{*}{ PMM } & Native & 59 & 65 \\
& Non-native & 11 & 9 \\
& Woody & 9 & 15 \\
\hline
\end{tabular}

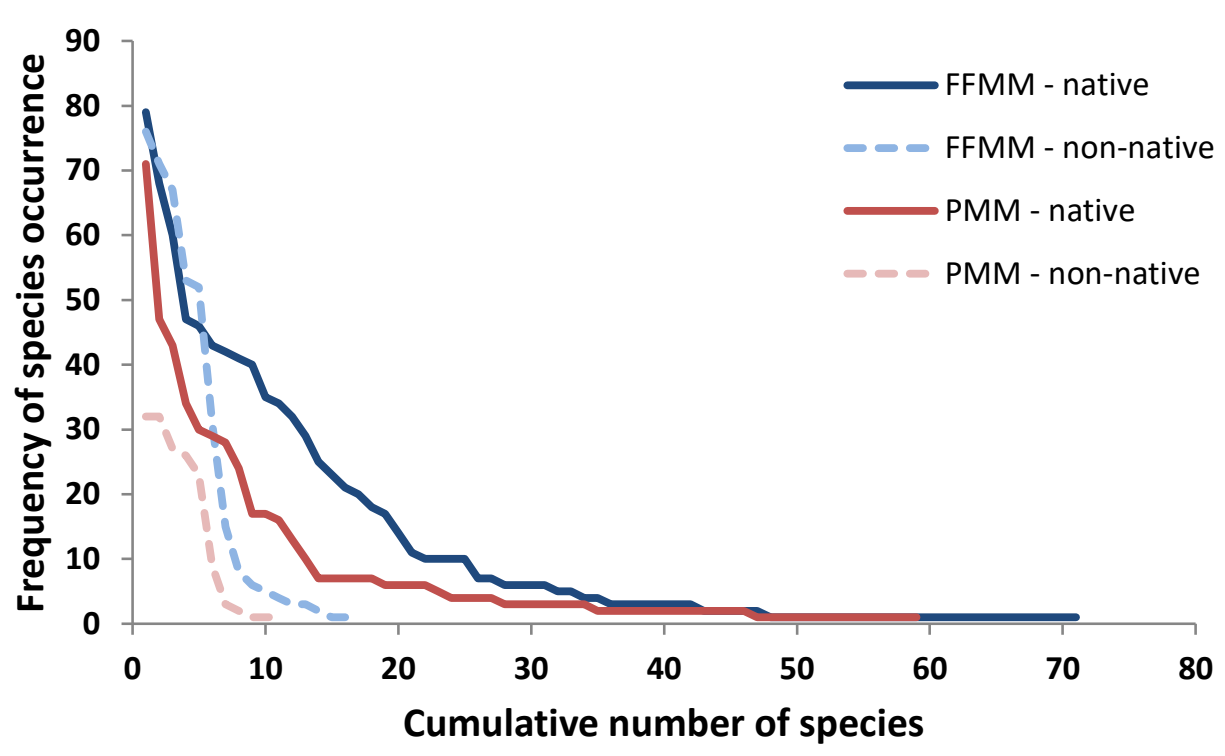

Figure 4. Frequency of species occurrence in all transect quadrats combined ( $n=110$ for FFMM and $n=130$ for PMM) by soil type in the one-year-old Islands site.

Non-native species richness shows differences by soil type only for the one-year-old site with greater non-native richness in FFMM. However, at the five-year-old site non-native richness is similar among all plots (Fig. 3b). The most common non-native species were the same between soil types with Sonchus uliginosa, Chenopodium album, and Crepis tectorum being the most common in the one-year-old site and Sonchus, Crepis and Melilotus alba being the most common in the five-year-old site. There were also relatively few rare non-native species in both FFMM and PMM with the four most common species comprising $69 \%$ of the total non-native plant occurrences (Fig. 4). 
Woody species richness was greater on PMM than FFMM at both sites, and overall woody richness was greater at the older site (Fig. 3c). However, variability of woody species richness was greater on FFMM than PMM $(\mathrm{CV}=0.475$ vs 0.276$)$ indicating the more stochastic nature of woody plant establishment on FFMM reclamation soil. The most common woody species were also similar between soil types and between the one- and five-year-old sites with Picea glauca, Populus spp., Salix spp., and Rosa acicularis being the most common. The total woody species pool is very similar in number between soil types and increased over time (Table 2).

\section{Discussion}

Differences in soil and site characteristics were pronounced between the FFMM and PMM reclamation soils confirming past findings of greater plant diversity in FFMM (Mackenzie and Naeth, 2010) and greater deciduous tree seedling establishment in PMM (Pinno and Errington, 2015). This indicates that the soils used in the Islands design are typical of reclamation sites in the region and are therefore a suitable test site for evaluating the ecological responses to this new spatial pattern of reclamation soil placement.

The higher diversity of plant species in the FFMM relative to PMM is an example of lifeboating or banking of species from the pre-disturbance forest to the new forest (Vanha-Majamaa and Jalonen, 2001) through the propagules, including seeds, roots, and rhizomes, stored in the forest floor and upper mineral soil horizons (Whittle et al., 1997). The soils and associated propagules were physically salvaged during mining operations and then directly placed on the new reclamation site. Stockpiling of FFMM for long periods of time may reduce the viability of these propagules. In terms of the optimal size of FFMM patches, a minimum patch size of $671 \mathrm{~m}^{2}$ appears necessary to capture $75 \%$ of native species diversity in the largest FFMM reclamation patch. Interestingly, the diversity of native species in a nearby aspen-dominated mixedwood disturbed by fire in 2011 was along the same species area curve with 58 species found in approximately 1,800 $\mathrm{m}^{2}$ surveyed (Li et al., 2014) indicating that diversity patterns in FFMM are similar to those found in natural forests.

This propagule transfer process in FFMM appears to be critical for the establishment of herbaceous understory plants, which comprise the majority of plant richness in these boreal ecosystems. However, these native herbaceous species are mainly forest understory species which require shaded conditions so they may not do well in the longer term in exposed environments such as reclamation areas. The fact that there are fewer native species in the higher tree density 


\section{JASMR, 2016 Volume 5 Issue 1}

PMM and a smaller increase in species number over time indicates that shady understory conditions are not immediately critical in the establishment and survival of these understory plant species. The greater increase in species richness over time in FFMM also indicates that some

species may establish from the propagule bank over a longer time period (> one year) than expected. In the long term however, an important consideration will be the establishment of native plant diversity in PMM.

The establishment of woody species, and especially trees, is a critical component for forest reestablishment but there is lower woody species diversity in the boreal forest relative to herbaceous species. The greater woody species richness on PMM is likely due to the greater number of species seeding in from off-site either through windblown seeds (e.g., Populus spp., Salix spp.) or animal/bird dispersal (e.g., Cornus sericea, Rosa acicularis) which have very exacting seedbed requirements. For example, trembling aspen has a tiny seed and requires a constant supply of available water and low competition for germination and early establishment (McDonough, 1979). These conditions are met frequently on PMM with higher soil water content and lower competing leaf area, but occur less frequently on FFMM.

For non-native species, a smaller area than for native species is needed for establishment of $75 \%$ of the maximum species pool, likely due to the highly dispersed seeds and rapid establishment of weedy species such as Sonchus and Chenopdium (Lemna and Messersmith, 1990; Bassett and Crompton, 1978). Elimination of some non-native species was also evident between years one and five with Chenopodium (and other less common weedy species such as Kochia scoparia, Salsola kali, and Polygonum lapathafolium) being far less common in year five than year one. These are species that are capable of rapidly colonizing disturbed areas but are not able to maintain themselves on site, so-called passengers that colonize disturbed areas temporarily but likely do not alter ecosystem processes (MacDougall and Turkington, 2005). In terms of weed management, other species including Sonchus, Crepis, Melilotus, and Taraxacum officianale are well established in the five-year-old site and likely represent a more substantial longer term risk to forest development as these species may be capable of driving ecosystem changes.

Species richness at the quadrat scale is clearly driven by the infrequent occurrence of rare native species which explains why larger patch sizes are needed to achieve desired levels of native species diversity relative to non-natives of which there are fewer rare species. While we have focused mainly on the quadrat scale alpha diversity of the different soil types individually, the 
spatial pattern created by the Islands approach will also increase the beta diversity across the landscape by offering a greater variety of site types. Variability in patch sizes may also be an approach which would emulate the range of residual patch sizes found after wildfire (Lentile et al., 2005). This variability in diversity is often not considered in assessing reclamation outcomes but may offer a more resilient future landscape if a heterogeneous future forest alters fire susceptibility (Ryan, 2002) or risk of insect attack (Coulson et al., 1999). Another spatial consideration at a larger scale is the proximity of newly reclaimed areas to natural forests and mature reclaimed forests which may provide another source of propagules for the newly reclaimed forests. These landscape design options should be considered in long-term reclamation and mine closure planning.

\section{Operational Recommendations}

The focus of this initial research on the new Islands reclamation design was to begin quantifying the optimal size and spacing of the high diversity FFMM patches. Our results indicate that patch sizes of between 671 and $960 \mathrm{~m}^{2}$ are a minimum for ensuring initial establishment of native plants, including woody species, and decreasing the relative proportion of non-native weedy species. In terms of the spatial arrangement of patches, it appears that there is little initial movement of plants between the high diversity FFMM and surrounding PMM so closer patches are desirable in terms of plant diversity, but minimum spacings are likely restricted by equipment movement and soil availability constraints. As the limited availability of FFMM restrains patch sizes and spacing, another approach would be to increase the amount of edge between soil types by increasing the perimeter to area ratio with "fingers" of FFMM possibly favouring more vegetative expansion into nearby PMM, but this has yet to be tested. The limited FFMM soil may also be used in a layering approach with a base of PMM topped with a shallower (i.e., 5-10 cm) layer of FFMM to act as a surrogate forest floor. The forest floor is a defining feature of forest soils but it is missing from newly reclaimed soils so this layered approach may more closely mimic natural forest soils and allow for a greater area to be covered by the high diversity potential FFMM.

In terms of operational constraints of the Islands approach, future reclamation areas could be less structured without the layout of pre-determined patches as this was very time consuming and expensive due to increased survey and equipment costs. Future reclamation areas will use practical, cost-effective operations to implement the Islands design rather than the highly structured approach used for this initial implementation. Similar to the rough and loose approach, randomly dumping loads of FFMM within a matrix of PMM may serve to recreate the important 
aspects of the Islands design, including the high diversity patches, conservation of limited FFMM soil, and increasing overall landform diversity, at a much lower cost. Overall, the initial results from this new oil sands reclamation design are very promising and are being used to help guide the development of future reclamation areas.

\section{$\underline{\text { Acknowledgements }}$}

We thank Edith Li, Pamela Freeman, and Stephanie Jean for field and lab work and Anthony Taylor for reviewing an earlier draft of this manuscript. Funding for this work was provided by Canadian Natural Resources Limited and Natural Resources Canada.

\section{$\underline{\text { References }}$}

Alberta Environment and Water. 2012. Best Management Practices for Conservation of Reclamation Materials in the Mineable Oil Sands Region of Alberta. Prepared by D. MacKenzie for the Terrestrial Subgroup, Best Management Practices Task Group of the Reclamation Working Group of the Cumulative Environmental Management Association. 9 March 2011. Fort McMurray, Alberta.

Archibald, H.A. 2014. Early ecosystem genesis using LFH and peat cover soils in Athabasca Oil Sands reclamation. M.Sc. thesis, Department of Renewable Resources, University of Alberta, Edmonton, Alberta.

Audet, P., B.D. Pinno, and E. Thiffault. 2015. Reclamation of boreal forest after oil sands mining: anticipating novel challenges in novel environments. Canadian Journal of Forest Research. 45:363-370. http://dx.doi.org/10.1139/cjfr-2014-0330.

Baker, S.C., C.B. Halpern, T.J. Wardlaw, R.L. Crawford, R.E. Bigley, G.J. Edgar, S.A. Evans, J.F. Franklin, G.J. Jordan, Y. Karpievitch, T.A. Spies, and R.J. Thomson. 2015. Short- and longterm benefits for forest biodiversity of retaining unlogged patches in harvested areas. Forest Ecology and Management. 353:187-195. http://dx.doi.org/10.1016/j.foreco.2015.05.021.

Bassett, I.J. and C.W. Crompton, 1978. The biology of Canadian weeds. 32. Chenopodium album L. Canadian Journal of Plant Science. 58:1061-1072. http://dx.doi.org/10.4141/cjps78-161. 
Beckingham, J.D. and J.H. Archibald. 1996. Field guide to ecosites of northern Alberta. Natural Resources Canada, Canadian forest Service, Northwest Region, Northern Forestry Centre, Edmonton, Alberta. Special Report 5.

Bradbury, S. 2004. Understorey plant communities in boreal cutblocks with different sizes and numbers of residual tree patches. Canadian Journal of Forest Research. 34:1220-1227. http://dx.doi.org/10.1139/x04-010.

Burley, J.B., C. Churchward, C.J Burley, and W.D. Sanders. 20015. Lower Grey Cloud Island forest patch: a 20 year reclamation monitoring study. Proceedings of the American Society of Mining and Reclamation, 2005: 146-153. http://dx.doi.org/10.21000/JASMR05010146

Coulson, R.N., B.A. McFadden, P.E. Pulley, C.N. Lovelady, J.W Fitzgerald,. and S.B. Jack. 1999. Heterogeneity of forest landscapes and the distribution and abundance of the southern pine beetle. For. Ecol. Manage. 114:471-485. http://dx.doi.org/10.1016/S0378-1127(98)00376-4.

Delong, S.C. and D Tanner. 1996. Managing the pattern of forest harvest: lessons from wildfire. Biodiv. Cons. 5:1191-1205. http://dx.doi.org/10.1007/BF00051571.

Errington, R.C. and B.D. Pinno. 2016. Early successional plant community dynamics on a reclaimed oil sands mine in comparison with natural boreal forest communities. Ecoscience. Published online. http://dx.doi.org/10.1080/11956860.2016.1169385

Government of Alberta. 2015. Oil sands reclamation fact sheet. January 2015. www.oilsands.alberta.ca

Gustafsson, L., S.C. Baker, J. Bauhus, W.J. Beese, A. Brodie, J. Kouki, D.B. Lindenmayer, A. Lohmus, G. Martinez Pastur, C. Messier, M. Neyland, B. Palik, A. Sverdrup-Thygeson, W.J.A. Volney, A. Wayne, and J.F. Franklin, 2012. Retention forestry to maintain multifunctional forests: A world perspective. BioScience. 62:633-645. http://dx.doi.org/10.1525/bio.2012.62.7.6.

Hart, S.A. and H.Y.Y Chen. 2006. Vegetation dynamics of North American boreal forests. Crit. Rev. Plant Sci. 25:381-397. http://dx.doi.org/10.1080/07352680600819286.

Huggard, D.J., B.E. Grover, E. Dzus, M. Smith, and J. Schiek. 2015. Effectiveness monitoring for biodiversity: comparing 15 year old structural retention harvest areas to fires in boreal aspen. Canadian Journal of Forest Research. 45:153-161. http://dx.doi.org/10.1139/cjfr-2014-0091. 
Lemna, W.K. and C.G. Messersmith. 1990. The biology of Canadian Weeds. 94. Sonchus arvensis L. Canadian Journal of Plant Science. 70:509-532. http://dx.doi.org/10.4141/cjps90-060.

Lentile, L.B., F.W. Smith, and W.D. Shepperd. 2005. Patch structure, fire-scar formation, and tree regeneration in a large mixed-severity fire in the South Dakota Black Hills, USA. Can. J. For. Res. 35:2875-2885. http://dx.doi.org/10.1139/x05-205.

Li, E. B. Pinno, R. Errington, R. Krygier, and N. Startsev. 2014. CNRL Reclamation Research Annual Progress Report 2013-2014: Trembling aspen seedling establishment on reclaimed sites. Natural Resources Canada, Canadian Forest Service. Edmonton, AB.

MacDougall, A.S. and R. Turkington. 2005. Are invasive species the drivers or passengers of change in degraded ecosystems? Ecology. 86:42-55. http://dx.doi.org/10.1890/04-0669.

Mackenzie, D.D. and M.A. Naeth. 2010. The role of the forest soil propagule bank in assisted natural recovery after oil sands mining. Restoration Ecology 18: 418-427. http://dx.doi.org/10.1111/j.1526-100X.2008.00500.x.

Macyk, T.M. and B.L. Drozdowski. 2008. Comprehensive report on operational reclamation techniques in the mineable oil sands region. Prepared for the Soil/Vegetation Subgroup of the Reclamation Working Group of the Cumulative Environmental Management Association. Fort McMurray, AB.

McDonough, W.T. 1979. Quaking aspen - seed germination and early seedling growth. USDA Forest Service, Research Paper INT-234.

Pinno, B.D. and R.C. Errington. 2015. Maximizing natural deciduous tree seedling establishment on a reclaimed oil sands site. Ecological Restoration. 33:43-50. http://dx.doi.org/10.3368/er.33.1.43.

Powell, K.I., J.M. Chase, and T.M. Knight. 2013. Invasive plants have scale-dependent effects on diversity by altering species-area relationships. Science. 339:316-318. http://dx.doi.org/10.1126/science.1226817.

Ryan, K.C. 2002. Dynamic interactions between forest structure and fire behavior in boreal ecosystems. Silva Fennica. 36:13-39. http://dx.doi.org/10.14214/sf.548. 
JASMR, 2016 Volume 5 Issue 1

Vanha-Majamaa, I. and J. Jalonen. 2001. Green tree retention in Fennoscandian forestry. Scandinavian Journal of Forest Research Supplement. 3:79-90. http://dx.doi.org/10.1080/028275801300004433.

Venier, L.A. and J.L. Pearce. 2007. Boreal forest landbirds in relation to forest composition, structure, and landscape: implications for forest management. Can. J. For. Res. 37:1214-1226. http://dx.doi.org/10.1139/X07-025.

Whittle, C.A., L.C. Duchesne, and T. Needham. 1997. The importance of buried seeds and vegetative propagation in the development of postfire plant communities. Environ. Rev. 5:7987. http://dx.doi.org/10.1139/a97-003. 